\title{
Extraction, characterization and evaluation of saponin-based natural surfactant for enhanced oil recovery
}

\author{
Happiness Imuetinyan ${ }^{1} \cdot{\text { Augustine } \text { Agi }^{1,2} \text { - Afeez Gbadamosi }}^{3} \cdot$ Radzuan Junin $^{1,2}$
}

Received: 19 September 2021 / Accepted: 8 December 2021 / Published online: 22 January 2022

(c) Saudi Society for Geosciences 2022

\begin{abstract}
To minimize environmental impact and costs, natural surfactants are suggested as an ecologically sustainable replacement for synthetic surfactants. The aim of this work is to evaluate the efficiency of low-cost saponin-based natural surfactant (SBNS) from Vernonia amygdalina (VA) leaves for enhanced oil recovery (EOR). Furthermore, the study investigated the IFT behaviour of SBNS at oil-water interface and the emulsion behaviour and oil displacement efficiency of SBNS. The SBNS was obtained via ultrasonic extraction of dried VA leaves in a water bath, centrifuging the obtained liquid mixture and freeze drying to evaporate to dryness. Thereafter, Fourier-transform infrared spectroscopy (FTIR) and high-performance liquid chromatography were used to characterize the extracted SBNS. Moreover, tensiometer (Easy-Dyne KRUSS) was used to study the interfacial tension (IFT) behaviour of the SBNS at oil-water interface. Also, the SBNS ability to form stable emulsion in the presence of crude oil was determined. Finally, oil displacement by SBNS solution was investigated under simulated reservoir conditions $\left(3000 \mathrm{psi}\right.$ and $100^{\circ} \mathrm{C}$ ) with high-pressure high-temperature (Fars EOR) core flooding equipment. The performance of SBNS was compared to commercial non-ionic surfactant 4-octylphenol polyethoxylated (TX-100). Experimental result indicated that the SBNS reduced the IFT at oil-water interface. The natural surfactant lowered the IFT of the oil-water interface from 18.0 to $0.97 \mathrm{mN} / \mathrm{m}$. Moreover, emulsions formed with SBNS showed good stability characterized by a decrease in the median drop diameter with an increase in SBNS concentration. Finally, oil displacement test shows that oil recovery of TX-100 and SBNS increased by $9 \%$ and 15\% original-oil-in-place (OOIP), respectively. Hence, SBNS is recommended as an appropriate substitute for conventional surfactant due to its inexpensive raw material, lower toxicity, and higher efficiency.
\end{abstract}

Keywords Enhanced oil recovery $\cdot$ Surfactant, Interfacial tension, Ultrasonic extraction $\cdot$ Emulsion $\cdot$ Saponin

\section{Introduction}

Responsible Editor: Santanu Banerjee

Afeez Gbadamosi

gbadamosiafeezo@gmail.com; r-radzuan@utm.my

$\triangle$ Radzuan Junin

gbadamosiafeezo@gmail.com; r-radzuan@utm.my

1 Department of Petroleum Engineering, School of Chemical and Energy Engineering, Faculty of Engineering, Universiti Teknologi Malaysia, 81310 Johor Bahru, Malaysia

2 Institute for Oil and Gas (IFOG), Universiti Teknologi Malaysia, 81310 Johor Bahru, Malaysia

3 Center for Integrative Petroleum Research, King Fahd University of Petroleum and Minerals, Dhahran 31262, Saudi Arabia
With the restarting of major economies post COVID-19, the global demand for energy has increased. More importantly, oil and gas continue to contribute a significant quota of world energy supply for developed and developing countries (Agi et al. 2018; Aydin 2014, 2015). The estimated average cost of developing a new well is increasing; hence, there is fewer exploration of new oil and gas fields. Meanwhile, literature suggests that about 50 to $70 \%$ oil originally in place (OOIP) is still stuck in the reservoir after initial recovery and water flooding process (Olajire 2014). Hence, alternative ways to increase oil production economically are prodigiously being investigated (Agi et al. 2020a, b). Hitherto, various EOR processes, such as chemical, thermal and gas, have been used to boost the recovery of oil (Guo et al. 2016; Adil et al. 2018; Gbadamosi et al. 2019a; Wang et al. 
2021a, b). Chemical EOR (CEOR) technology is believed to be potentially beneficial due to the increasing expertise, rational cost of capital, functional and financial capabilities (Wang et al. 2021a, b; Zhong et al. 2020; Gbadamosi et al. 2019b; Agi et al., 2020a).

The notable CEOR methods involve the use of alkalis, polymers and surfactant (Dong et al. 2009; Gbadamosi et al. 2018). Surfactant EOR method aids oil recovery by altering the rock/fluid and fluid/fluid properties in the porous media (Abbas et al. 2018; Hussein et al. 2018; Massarweh and Abushaikha 2020). Consequently, interfacial tension (IFT) reduction and emulsification occur at the interface of oil and water $(\mathrm{O} / \mathrm{W})$ while the alteration of wettability of the reservoir rock to water-wet form occurs, thereby resulting in higher pore scale displacement efficiency (Abbas et al. 2020a, b). Nonetheless, the conventional chemicals used for CEOR present some limitations due to the differences in oil characteristics and harsh conditions in the reservoir (Gbadamosi et al. 2020). Also, the high cost of synthetic surfactant, environmental concerns and significant adsorption of synthetic surfactant onto rock surface has limited surfactant EOR development and the profitability of the process (Ferrari et al. 1998; Negin et al. 2017; Abbas et al. 2020a).

Natural surfactants based on plants have recently drawn attention in diverse areas to resolve the restrictions of synthetic surfactants owing to their low costs, availability and eco-friendly features (Ali et al. 2015). The O/W IFT and foaming properties of natural surfactant extracted from Anabasis setifera plant were investigated from a recent study by Nowrouzi et al. (2020). At critical micelle concentration (CMC), IFT was lowered from 25.608 to $1.066 \mathrm{mN} / \mathrm{m}$ and showed promising application for EOR. Pordel et al. (2012) examined surfactant extracted from Ziziphus spinachristi plant and reported an IFT decrement to $9 \mathrm{mN} / \mathrm{m}$ from $48 \mathrm{mN} / \mathrm{m}$ via pendant drop method. The major component of the plant responsible for the presence of surface-active nature was saponin. Yekeen et al. (2020) investigated the alteration of wettability, decrement in IFT, and foaming characteristics of saponin surfactant obtained from soapnut. A concentration of $0.2 \mathrm{wt} . \%$ of the biosurfactant reduced IFT of $\mathrm{O} / \mathrm{W}$ interface to 1.59 from $23.24 \mathrm{mN} / \mathrm{m}$. Besides, the foam generated by the saponin-based surfactant was stable at ambient condition and took longer time for $100 \%$ liquid drainage than conventional SDS-stabilized foam.

Vernonia amygdalina is a shrub tree found around the world and mainly in tropical regions of Africa and Asia (Uzoho et al. 2019). It is popularly referred to as bitter leaf because of its bitter taste (Odugbemi et al. 2007). The phytochemical analysis of an extract of $V$. amygdalina by Udochukwu et al. (2015) confirms the presence of saponin. Saponins are naturally occurring plant glycosides with strong foamability in aqueous solution (Sahu et al. 2011). The foamability is due to the non-polar sapogenin and water-soluble side chain which has a close resemblance in structure to most synthetic surfactants (Wieslaw and Arafa 2010). The lipophiles are usually like synthetic surfactant while the hydrophiles have varieties. The hydrophiles of saponins have sugar chain with different composition whereas the lipophiles have a steroidal or triterpene structure. This is the basis for classifying surfactants as anionic, cationic and non-ionic.

Hitherto, saponin has been extracted from various plants such as soap nuts (Chhetri et al. 2009; Banerjee et al. 2015; Saxena et al. 2018, 2019); Seidlitzia rosmarinus (Deymeh et al. 2012); Gylcyrrhiza glabra (Mohammad et al. 2012); Ziziphus spina-christi (Pordel et al. 2012; Mohsen et al. 2013); olive, spistan and prosopis (Ali et al. 2015) and Anabasis setifera (Nowrouzi et al. 2020) using conventional methods of extractions (Sievers and Eggers 1996). But these conventional methods have several shortcomings such as high solvent consumption, long extraction period, changes in characteristics of the extracted saponin, environmental and health risks. Maceration and Soxhlet extraction methods have difficulties in dealing with natural samples (Roy et al. 2013). The analytes bind more strongly in natural compound. As such, the best way to remedy the situation is the use of polar solvent such as methanol and ethanol. This polar solvent most of the time leaves unwanted residue of fat and oil on the final product, thus limiting their usability to the industry. Ultrasonic extraction enhances the extraction efficiency, increases antioxidant activity of the extract and avoids structural changes and degradation of the polysaccharides (Chemat et al. 2017; Peshkovsky and Bystryak 2014; Roy et al. 2013). It can be used with any solvent making it the preferred option in the extraction of natural compounds (Stevanato and Silva 2019).

Herein, a mechanistic study of ultrasonic extraction of saponin-based natural surfactant (SBNS) from V. amygdalina leaves using hot water as the solvent was performed and individually explored for EOR applications. The chemical structure and surface properties were determined. Qualitative and quantitative analysis of SBNS was compared with standard saponin. Since saponin is a nonionic surfactant, there is need to compare its EOR mechanisms and oil displacement efficiency with commercial non-ionic surfactant. Hence, the alteration of wettability and IFT properties of the SBNS at the O/W interface were compared with commercial non-ionic surfactant 4-octylphenol polyethoxylated (TX-100) at elevated temperature. TX-100 is the most revered non-ionic surfactant and has been used by previous studies as a basis for comparison with SBNS. The ability of SBNS to form emulsion in the presence of crude oil was explored. The oil displacement efficiency of SBNS solution at typical reservoir condition in comparison with TX-100 was studied. 


\section{Experimental}

\section{Materials}

Matured V. amygdalina leaves were harvested in August from Universiti Teknologi Malaysia (UTM) campus Johor Bahru, Malaysia (1 $1^{\circ} 33^{\prime} 19.79^{\prime \prime} \mathrm{N}$ and $\left.103^{\circ} 38^{\prime} 17.39^{\prime \prime} \mathrm{E}\right)$. Non-ionic surfactant (TX-100 of $96 \%$ purity) with mol. wt. of $646.37 \mathrm{~g} / \mathrm{mol}$ was supplied by Acros Organic company, USA. Ninety-nine per cent purity sodium chloride $(\mathrm{NaCl})$ with a mol. wt. of $58.44 \mathrm{~g} / \mathrm{mol}$ was acquired from Sigma Aldrich. For the analyses, an intermediate crude oil gotten from Sarawak oilfield, Malaysia $\left(4^{\circ} 6^{\circ} \mathrm{N}\right.$ and $110^{\circ} 112^{\circ} 114^{\circ}$ E) with a viscosity and density at $25^{\circ} \mathrm{C}$ of $10 \mathrm{mPa}$ s and 0.82 $\mathrm{g} / \mathrm{mL}$ (API 37.7), respectively, was applied. Table 1 shows the SARA property of the crude oil. Cores of sandstone of the same outcrop with mid-permeability were applied for the test of core flooding. Table 2 presents the physical form of the cores of the sandstone used in this study. Distilled (DW) and deionized water (DIW) were used as the solvent.

\section{Experimental test}

\section{Saponin extraction from V. amygdalina Leaves}

About $10 \mathrm{~kg}$ of $V$. amygdalina leaves was cleaned, air dried for 5 days and grinded into powder form. The powdered plant material was passed through a $0.5-\mathrm{mm}$ sieve. About 2 $\mathrm{g}$ of the powdered sample was dispersed in $100 \mathrm{ml}$ of DIW in a beaker. This was shaken for 2 min on an orbital shaker (Protech Model 720) after which the beaker was positioned in an ultrasonic water bath $(40 \mathrm{kHz}, 500 \mathrm{~W})$. The characteristics of the ultrasonic power and measurement of the water bath can be found somewhere else (Agi et al. 2018b, 2019a). The extraction was done for $2 \mathrm{~h}$ during which the bath temperature was between 27 and $35^{\circ} \mathrm{C}$. After extraction, the liquid samples were transferred into 50-ml conical

Table 1 Crude oil SARA Properties

\begin{tabular}{llllll}
\hline $\begin{array}{l}\text { Volatiles } \\
(\%)\end{array}$ & $\begin{array}{l}\text { Inorgan- } \\
\text { ics }(\%)\end{array}$ & $\begin{array}{l}\text { Saturates } \\
(\%)\end{array}$ & $\begin{array}{l}\text { Aromat- } \\
\text { ics }(\%)\end{array}$ & $\begin{array}{l}\text { Resins } \\
(\%)\end{array}$ & $\begin{array}{l}\text { Asphaltenes } \\
(\%)\end{array}$ \\
\hline 79.83 & 0.06 & 11.02 & 2.73 & 6.35 & 0.01 \\
\hline
\end{tabular}

polypropylene centrifuge tube and centrifuged (Sorval, Wx 100 plus + Ultra Series) at $2000 \mathrm{rpm}$ for $20 \mathrm{~min}$. The liquid extracted $(50 \mathrm{ml})$ was then collected using an ash-less filter paper. It was then placed in a freeze dryer to evaporate to dryness under vacuum at $45^{\circ} \mathrm{C}$.

\section{Chemical structure and surface properties}

The functional groups of the extracted saponin (SBNS) were studied using Tracer 100 Fourier-transform infrared spectroscopy (FTIR-Shimadzu IR). Before placing the dried SBNS in a sample container, it was first introduced into potassium bromide $(\mathrm{KBr})$ before it was placed in a sample bearer, and the FTIR spectra were attained from a waverange of $500-4000 \mathrm{~cm}^{-1}$.

\section{HPLC analysis}

The SBNS (0.1 wt.\%) was diluted 3-fold using DIW and filtered through a $0.45-\mu \mathrm{m}$ syringe filter before injection. The chromatograph was acquired from the HPLC system using UV-Vis detector run at $0.8 \mathrm{~mL} / \mathrm{min}$. The mobile phase is a buffer solution of o-phosphoric acid with a pH of 2.4 for 30 $\mathrm{min}$. The total saponin was detected and quantified at 280 $\mathrm{nm}$ and compared with standard saponin.

\section{IFT and CMC measurement}

IFT in the presence of SBNS (0.1-3 wt.\%) was measured using the tensiometer of Easy Dyne obtained from Kruss $\mathrm{GmbH}$, Germany. The ring correction process by Harkins and Jordan was applied to calibrate the equipment. Thereafter, the IFT of oil-water interface was measured in the presence of SBNS. The value of the CMC was determined from IFT-surfactant concentration plot at the inflection point above which no substantial variation in IFT was measured.

\section{Emulsion stability test}

Test of emulsion stability was conducted for investigating the proficiency of emulsion of SBNS to withstand a possible modification in the physicochemical nature of the SBNS with time for applicability in EOR. SBNS solution was formulated for seven different concentrations $(0.1-3 \mathrm{wt} . \%)$. Ten millilitres of SBNS solution and $10 \mathrm{ml}$ of crude oil were
Table 2 Properties of sandstone core used for flooding test

\begin{tabular}{lllllll}
\hline Test No. & Diameter $(\mathrm{cm})$ & Length $(\mathrm{cm})$ & Bulk volume $\left(\mathrm{cm}^{3}\right)$ & $\begin{array}{l}\text { Pore } \\
\text { volume } \\
\left(\mathrm{cm}^{3}\right)\end{array}$ & Porosity $(\%)$ & Permeability $(\mathrm{mD})$ \\
\hline 1 & 3.7 & 9.7 & 104.3 & 17 & 16.2 & 167.43 \\
2 & 3.7 & 9.9 & 105.37 & 17 & 16.1 & 165.24 \\
\hline
\end{tabular}


mixed and stirred to get a homogenous phase. The mixture was sonicated for $10 \mathrm{~min}$ as previously described. The mixture was placed in a centrifuge tube and stored undisturbed for $120 \mathrm{~h}$ to allow the phases to be separated under gravity. Thereafter, the image of the emulsifying ability of the SBNS (120 hours) was captured. To determine the effect of salinity on SBNS emulsion, $10 \mathrm{ml}$ of SBNS solution at CMC was mixed with $10 \mathrm{ml}$ of crude oil to form emulsion at different salinity concentration (0.9-2.2 wt.\%). The emulsion was sonicated and stored in the oven at $80{ }^{\circ} \mathrm{C}$ to investigate the stability of the emulsion. Thereafter, the images of the mix were captured $(120 \mathrm{~h})$. The emulsion conductivity was determined using a JENWAY 3540 digital conductivity meter. The drop size distribution of SBNS emulsion was determined using a litesizer ${ }^{\mathrm{TM}} 500$ Anton Paar equipment. The equipment determines the emulsion size distribution by calculating diffusion rate of the emulsion using Stokes-Einstein equation. The measurement was achieved at three concentrations below CMC (0.1 wt.\%), at CMC (1 wt.\%) and above CMC (3 wt.\%) of SBNS solution. The diffusion of the particles moving under Brownian motion was determined and converted to the hydrodynamic diameter $\left(d_{h}\right)$ of the emulsion droplets using Stock-Einstein equation 2(Saxena et al. 2018):

$d_{h}=\frac{k_{b} T}{3 \pi \eta D}$

whereas $k_{b}$ is Boltzmann constant, $D$ is diffusion coefficient, and $\eta$ is viscosity at temperature $T$.

\section{Core flooding test}

Core floods were determined by means of a high-pressure high-temperature (HPHT) equipment produced by Fars EOR technology. It was made of a temperature control furnace, four fluid injection accumulators and a core holding compartment. It has a pressure power and temperature bounds of $6000 \mathrm{psi}$ and $150{ }^{\circ} \mathrm{C}$, respectively. Three similar core samples of mid-permeabilities from similar outcrop as those used for the test of contact angle were applied in the measurement of oil displacement, and their properties are depicted in Table 2. Core samples were cleaned using toluene in the distillation column of Soxhlet extractor before and after each application. The cores were then dried in an oven at $80{ }^{\circ} \mathrm{C}$ for $24 \mathrm{~h}$. Test for displacement of oil for oil recovery efficiency of SBNS and TX-100 was conducted. The tests were performed in $3000 \mathrm{psi}$, with overburden pressures of $100 \mathrm{psi}$ and a temperature on the oven up to $100{ }^{\circ} \mathrm{C}$ to mimic the state of the reservoir. The process was later saturated and flooded with oil with $2 / .2 \mathrm{wt} . \%$ of synthetic brine $(\mathrm{NaCl})$, until connate water was reached. In pump injectors from injectants to equipment, ISCO pump was used. At 0.5 $\mathrm{mL} / \mathrm{min}$, crude oil was introduced into the core to represent a laminar flow (Shiran and Skauge 2013; Kumar and Mandal 2018; Risal et al. 2019; Agi et al. 2019b; Bila et al. 2020). The system was heated for $24 \mathrm{~h}$ to reach equilibrium. Then before the breakthrough, water was pumped at a steady flow rate. Subsequently, to extract the trapped oil, $0.5 \mathrm{PV}$ of 1.0 wt.\% SBNS and 0.2 wt.\% of surfactant TX-100 were each injected. To extract any leftover oil, $0.5 \mathrm{PV}$ chase water was injected into the system. All tests were repeated once, and the mean values indicated. The schematics of the experiment are depicted in Figure 1.

\section{Results and discussion}

\section{Mechanisms of SBNS ultrasonic extraction}

Fig. 2a shows the fresh leaves of $V$. amygdalina before drying whereas Fig. 2 shows the dried leaves before extraction. Table 3 shows the basic properties of the saponin obtained. The total amount of saponin extracted from $V$. amygdalina was calculated to be approximately $32 \pm 0.05 \%$ which is three times the $10.6 \%$ reported by Balakrishnan et al. (2006) using super-critical $\mathrm{CO}_{2}$ method. The higher yield can be attributed to the ultrasonic, which is consistent with previous study of Hromadkova et al. (1999). They reported that use of ultrasonic ( $50 \mathrm{~g}$ of ethanol-insoluble plant residue in $450 \mathrm{~mL}$ of DW) can enhance the extract of polysaccharides to about $39 \%$. The extraction enhancement was due to the ultrasonic cavitation.

During ultrasonication of $V$. amygdalina in DIW, shear forces were produced inside the liquid and within the material. These forces resulted in the formation of cavitation bubbles within the fluid. Suspended solid promoted asymmetric growth and bubble collapse which might have generated micro-jets and boosted the extraction (Vinatoru et al. 2017). The collapsing bubbles act like a hammer-jet striking the $V$. amygdalina particles. It is the impact of the micro-jet during cavitation collapse that might have caused the rapid penetration as the solvent is driven into the particles. Consequently, this causes the enlargement of $V$. amygdalina cell by driving the solvent into the plant cell wall where the SBNS might have been dissolved and transported into the bulk solvent (Mason et al. 1996). Cavitation creates an eruption of the liquid which broke the cell wall of the $V$. amygdalina thereby increasing mass transfer of the SBNS (Alzorqi et al. 2017).

Additionally, during the application of ultrasound in DIW containing $V$. amygdalina leaves, rapid fragmentation occurs resulting in a direct solubilization of sapogenins due to decrease in particle size through ultrasonic. The fragmentation might also be adduced to interparticle collision from shockwaves created by the collapsing bubbles which might have increased the extraction rate and yield due to increase in surface area. Also, cavitation bubbles on the 
Figure 1 Research flow chart.

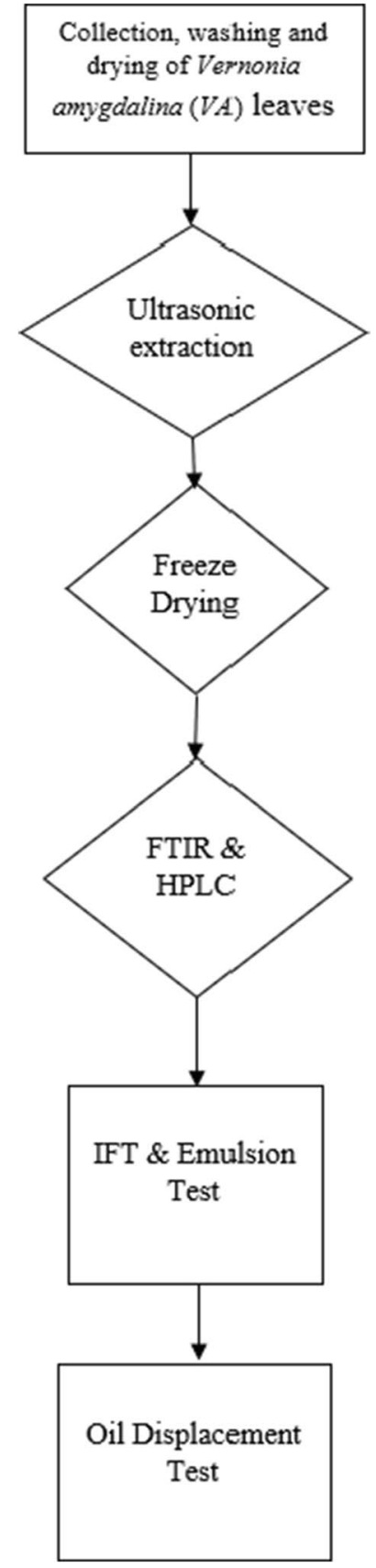

surface of the $V$. amygdalina might have induced erosion of $V$. amygdalina structures which is released to the extraction medium. Therefore, the ultrasonic created a sono-capillary effect which enhanced the basic mechanism of extractions (desorption and diffusion of the SBNS out of the V. amygdalina structure).

\section{Chemical structure and surface properties}

The presence of saponin was confirmed by FTIR spectra (Fig. 3). The result of the extracted saponin was compared with standard saponin (Fig. 3). The results show very close similarities with standard saponin (Fig. 3b). It showed absorbance of the hydroxyl group $(\mathrm{OH})$ at $3281 \mathrm{~cm}^{-1}$ for SBNS (Fig. 3a) compared to $3281 \mathrm{~cm}^{-1}$ in the standard saponin (Figure 2b). Absorption of carbon-hydrogen $(\mathrm{C}-\mathrm{H})$ was at $2926 \mathrm{~cm}^{-1}$ in the SBNS and $2924 \mathrm{~cm}^{-1}$ in standard saponin. The absorbance at $1557 \mathrm{~cm}^{-1}$ in the SBNS and $1588 \mathrm{~cm}^{-1}$ for standard saponin is characteristic of $\mathrm{C}=\mathrm{C}$. For $\mathrm{C}=\mathrm{O}$ absorbance, $\mathrm{SBNS}$ gave a value of $2116 \mathrm{~cm}^{-1}$ while the standard saponin was $1727 \mathrm{~cm}^{-1}$ (Sharma et al. 2012). The band at $1069 \mathrm{~cm}^{-1}$ for the SBNS and $1074 \mathrm{~cm}^{-1}$ in standard saponin is the $\mathrm{C}-\mathrm{O}-\mathrm{C}$, which is oligosaccharide linked to sapogenins. Hence, the result confirms that saponin is detectable in the extract.

\section{HPLC results}

Fig. 4a shows the HPLC result of SBNS. The chromatogram shows close similarity with standard saponin (Fig. 4b). The comparison of the spectra was done using the least square fit coefficient of the absorbances at the same wavelength.

Similarity $=1000 \times r^{2}$

$r=\frac{\sum_{i=1}^{i=n}\left[\left(A_{i}-A_{a v}\right) \times\left(B_{i}-B_{a v}\right)\right]}{\sqrt{\left[\sum_{i=1}^{i=n}\left(A_{i}-A_{a v}\right)^{2} \times \sum_{i=1}^{i=n}\left(B_{i}-B_{a v}\right)^{2}\right]}}$

whereas $A i$ and $B i$ are measured absorbances in the first and second spectrum respectively at the same wavelength, $n$ is number of data points, and $A a v$ and $B a v$ are average absorbance of the first and second spectrum, respectively. The similarity of 985.6 was observed with a spectral difference of $3.16 \%$. This shows the high purity of the extracted saponin. The peak at $280 \mathrm{~nm}$ matched that of a standard saponin confirming the presence of saponin in the extract of $V$. amygdalina. Comparison of the retention on both chromatograms indicates that the standard saponin has a retention time of 2.1 min whereas SBNS showed multiple retention time of 1.8, $1.9,2.5$, and 3.6 min (Table 4) which corresponds to common saponin constituents. The shorter retention time could be due to the ultrasonication. This is coherent with earlier work of Almutairi and Ali (2015) which reported that extraction techniques affect the retention time. This shows that the SBNS was not degraded by the ultrasonic, and the saponin content was unaltered and confirms the purity of SBNS. This conforms to the previous study of Li et al. (2007) where it was reported that ultrasonic can enhance the purity of polysaccharides by $28 \%$ compared to other methods. The enhancement is credited to the effectiveness of ultrasonic to improve bulk transmission rate of the polysaccharide. Consequently, this improves the extractability because of the action of cavitation on cell wall of $V$. amygdalina leaves. 
Fig. 2 a Fresh and b dried Vernonia amygdalina leaves before extraction
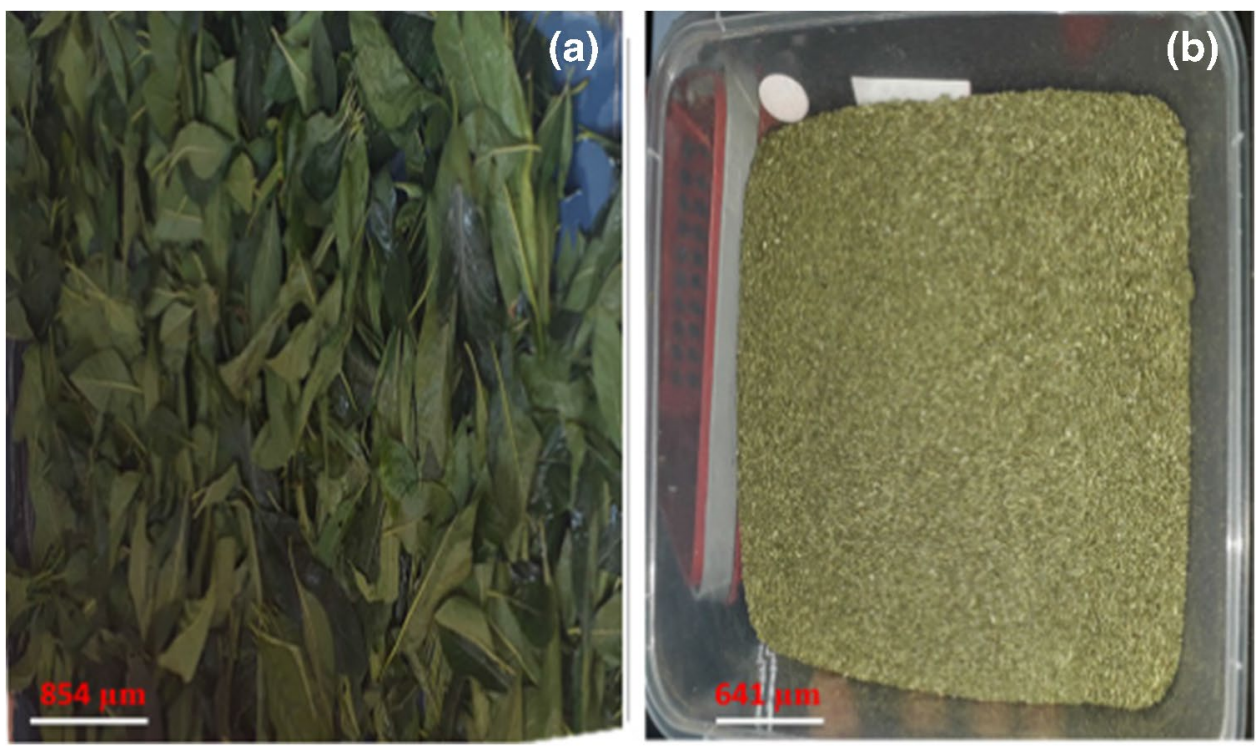

Table 3 Basic properties of extracted saponin

\begin{tabular}{ll}
\hline Parameters & Properties \\
\hline Description & Fine powder \\
Colour & Light brown \\
Solubility in water and alcohol & Soluble \\
Bulk Density & $0.1 \mathrm{~g} / \mathrm{mL}$ \\
pH (1wt\% solution) & 6.68 \\
\hline
\end{tabular}

\section{CMC determination of SBNS solutions}

Studies of the properties of solutions containing surfaceactive components have shown that properties of bulk solution can change drastically due to small changes in surfaceactive material concentrations (Ravera et al. 1997; Yekeen et al. 2019). These sudden changes in solution properties can be interpreted as an important change in the nature of the solute in solution. These observations provide evidence that micelles are formed in surfactant solution. The CMC signifies the concentration at which micelles are formed. This phenomenon occurs due to the saturation of the bulk solution with molecules of surfactant, and it determines the influence of the surfactant on IFT. The CMC of this study was determined at the point of inflection of the curve. As depicted in Fig. 5, the CMC value for SBNS is $1 \mathrm{wt} . \%$. From literature, the IFT of TX-100 is $0.2 \mathrm{wt} . \%$. The IFT of SBNS reduced as surfactant concentration increased until it reached $\mathrm{CMC}$, which is the concentration at which the surfactants can give its highest surface-active properties. This occurred due to the full saturation of the bulk solution with molecules of surfactant which led to the formation of micelles. The SBNS showed lower IFT at all concentrations and higher CMC. This was found to be caused by the SBNS molecule
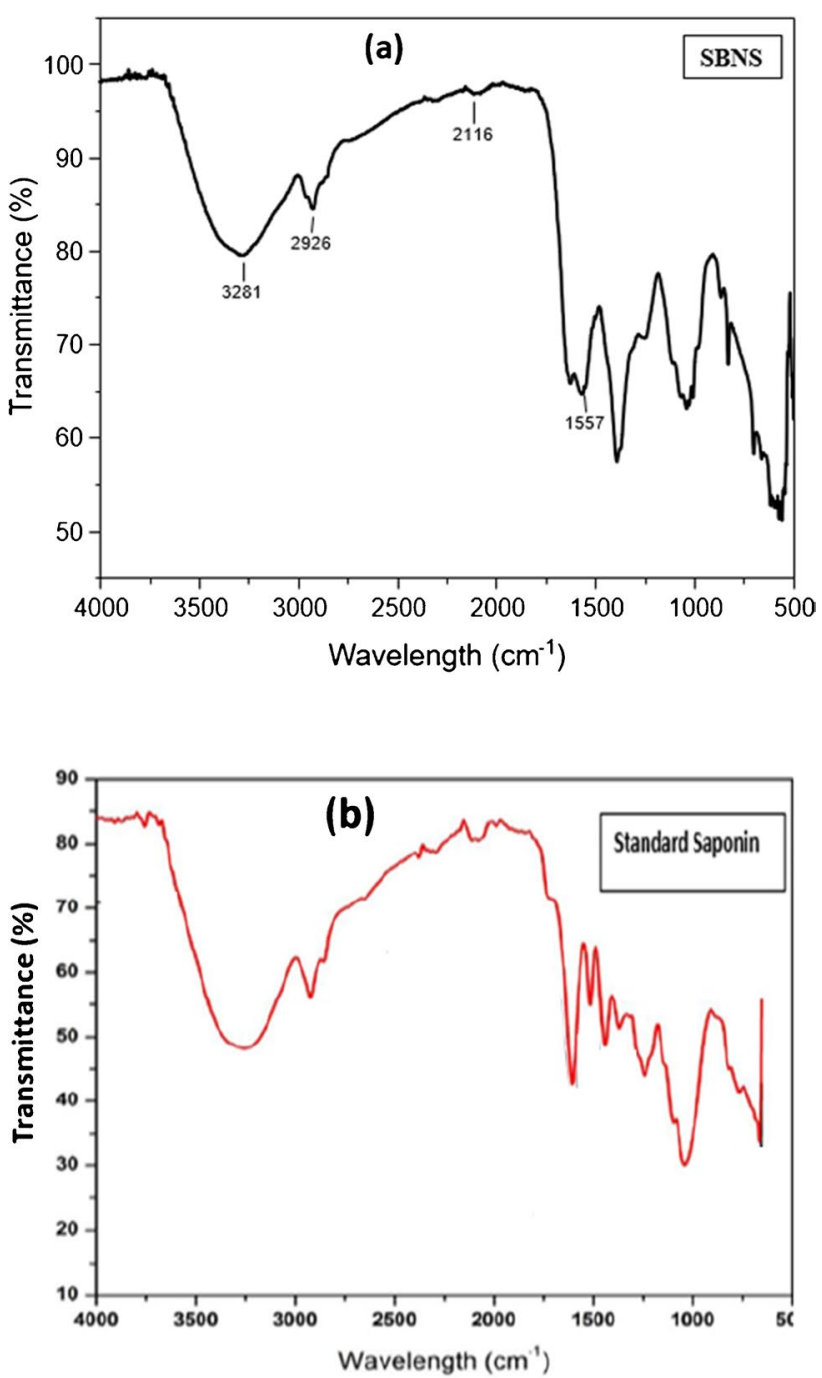

Fig. 3 a FTIR spectra for SBNS. b Standard saponin 

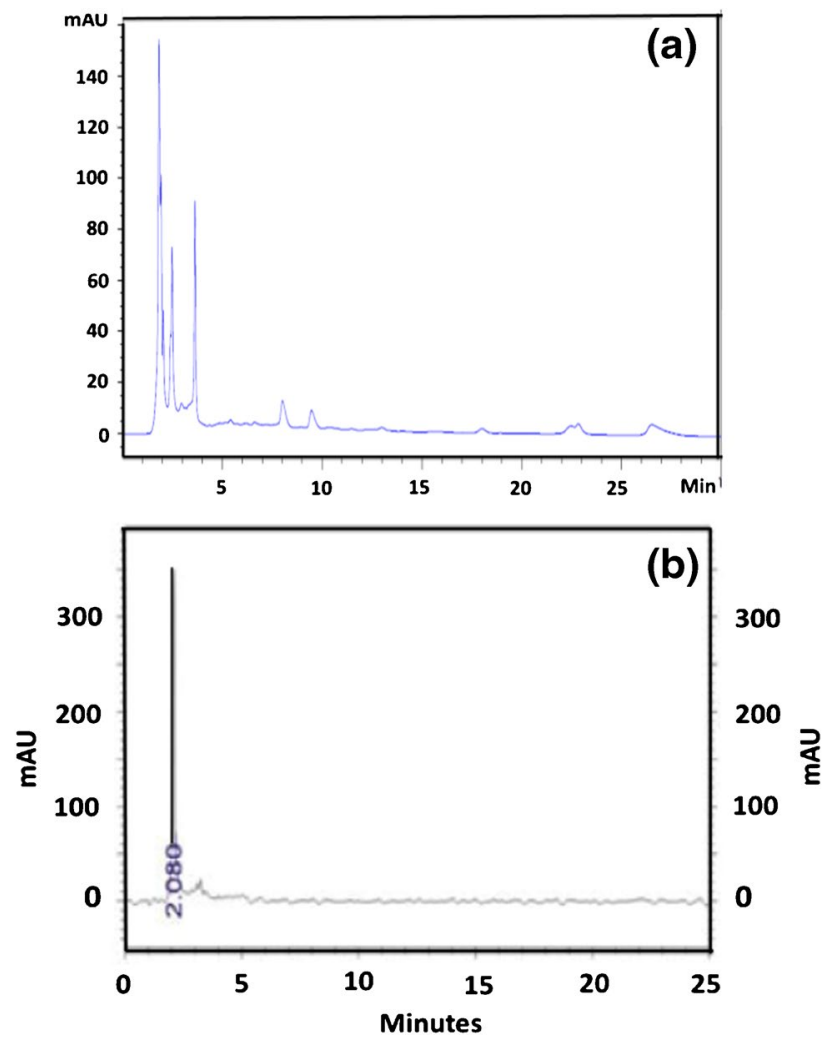

Fig. 4 a HPLC Analysis of SBNS. b Standard saponin

Table 4 Total saponin content extracted determined HPLC

\begin{tabular}{llc}
\hline Peak & Retention time (min) & Content $(\mathbf{w t} \%)$ \\
\hline 1 & 1.8 & 15.62 \\
2 & 1.9 & 7.33 \\
3 & 2.5 & 0.1 \\
4 & 3.6 & 9.28 \\
Sum & & $32 \pm 0.05$ \\
\hline
\end{tabular}

adsorption at the interface of $\mathrm{O} / \mathrm{W}$ with the hydrophilic sugar chain part of the molecules in the water face (Yekeen et al. 2009). The hydrophobic aglycone part of the molecule remains in the oil phase. This led to low dissociation of the carboxyl7ic group, high surface activity, foamability and emulsion stability which might have disrupted the cohesive energy at the interface and subsequently reduced the IFT.

The surface energy varied with SBNS concentration because of the SBNS molecule interaction at the interface and in the bulk solution which led to micelle formation (Saxena et al. 2019). This shows the ability of the SBNS to reduce capillary forces and increase oil mobilization. This conforms to the previous study by Ali et al. (2015) in which a CMC value of 1.9 wt.\% for surfactant from olive leaf was reported. The addition of SBNS to the solution concentration below the CMC increased the number of charge carrier in the solution and consequently led to increased conductivity. Addition of SBNS above the CMC increased the concentration of the micelle, whereas the concentration of the monomers remained constant at the CMC level. This is because of the micelle being larger than the SBNS monomer; hence, it diffuses slowly. This agrees with prior work by Oleszek and Hamed (2010) which observe a sudden change in physical properties of SBNS when the concentration surpassed the CMC. Therefore, for a surfactant flood to be favourable and economical, it is best applied above the CMC (Yekeen at al. 2019).

\section{Effect of salinity on IFT of SBNS}

The effect of different concentration of $\mathrm{NaCl}(0.9 \mathrm{wt} . \%, 1.5$ wt. $\%, 2.0$ wt. $\%, 2.2$ wt. $\%, 2.5$ wt. $\%$ and 3.0 wt. $\%$ ) on the IFT behaviour of SBNS was studied and reported in Fig. 6. The presence of $\mathrm{NaCl}$ reduces the IFT at the oil-water interface further. This can be adduced to salt-in effects. The inorganic salt breaks the structure of the water, thereby increasing the solubility of the organic components of the oil in the aqueous phase (Ghorbanizadeh and Rostami 2017). Besides, the presence of the ions increases the adsorption of the surfactant at the oil-water interface (Zaeri et al. 2019; Liu et al. 2018; Strand et al. 2006). Hence, the IFT of the oil-water interface reduces further. The IFT of the oil-water interface was lowest at optimum salinity of $2.2 \mathrm{wt} . \% \mathrm{NaCl}$ recorded as 0.97 $\mathrm{mN} / \mathrm{m}$ wherein the surfactant dissolves equally in aqueous and oleic phase resulting in the minimum IFT. Above 2.2 wt. $\% \mathrm{NaCl}$ concentration, the IFT of the oil-water interface increases with increasing brine concentration. Increasing brine concentration causes the movement of surfactant away from the oil-water interface, thus resulting in an increase in IFT (Kamal et al. 2017).

\section{Emulsion stability of SBNS solution}

The formation of emulsion by surfactants can result in low IFT. It increases miscibility with trapped oil, lowers the mobility of water and changes the pore and microscopic channel which can improve oil recovery. The emulsifying ability test was carried out at room temperature in centrifuge tubes to examine the ability of the SBNS solution to form emulsions. Fig. 7a shows the emulsion of various SBNS concentration solutions and crude oil with $\mathrm{O} / \mathrm{W}$ ratio $1: 1$ $(\mathrm{v} / \mathrm{v})$. It shows that all the concentration of SBNS could form emulsion with crude oil as no separation was noticed for $120 \mathrm{~h}$. All the emulsions were stable with no release to water being visible. Fig. $7 \mathrm{~b}$ shows the emulsion behaviour of SBNS at different salinity concentration (0.9-2.2 wt.\%). At low salinity concentration, SBNS full emulsion was still observed with no visible sign of separation. As the salinity 
Fig. 5 IFT as a function of surfactant concentration

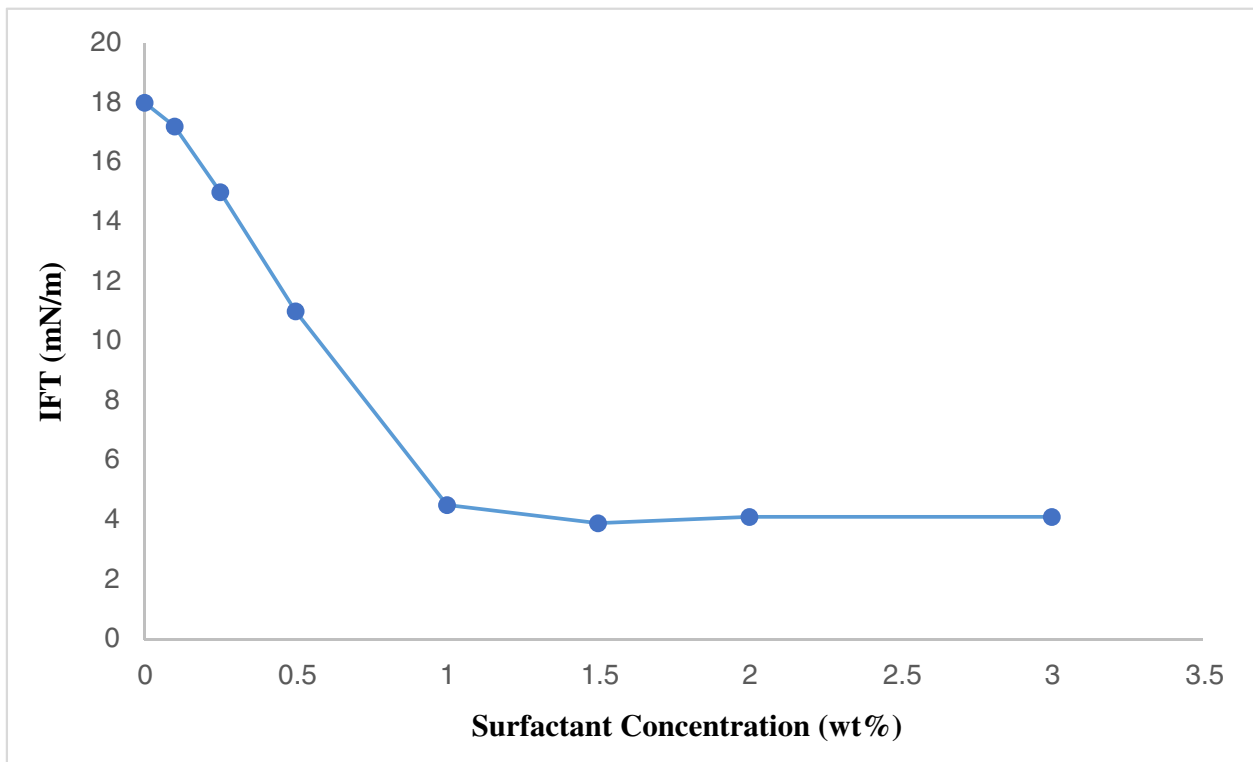

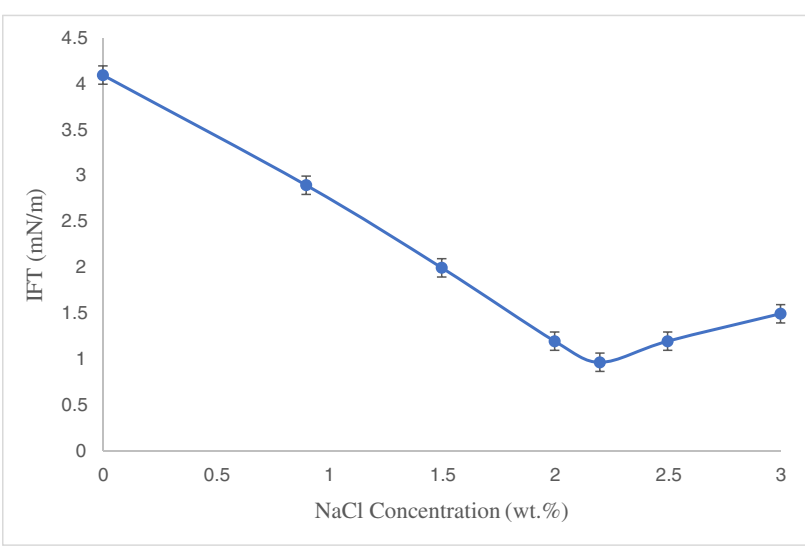

Fig. 6 Effect of salinity on IFT of SBNS

concentration increased, the lower end of the water external emulsion and the top phase of oil were created (Winsor type I). The middle phase emulsion stayed in balance with the excess oil phase at the top and the water phase at the bottom led to a bi-continuous phase at high salinity (Winsor type III). The result conforms to the earlier investigation of Saxena et al. (2019) which reported that the advantage of improving oil recovery is the creation of the Winsor III type phase. This signifies that the emulsions remained stable. The stability of the emulsions is due to the decrease in the median drop diameter with increase in SBNS concentration (Fig. 8).

The SBNS lowered the mean diameter of the emulsion. This shows the high stability of SBNS against creaming and coalescence (Trujillo-Cayado et al. 2014). This is consistent with the mechanisms of ultrasonic extraction as fragmentation and erosion led to increase in surface area and higher mass transfer resulting in higher yield and stable emulsion. It might also be because of the increase in viscosity with SBNS concentration of the continuous oil phase (Binks et al. 2005). This was evident as the SBNS concentration affected the conductivity of the emulsion (Fig. 9). The conductivity increased as the concentration of SBNS increased. This implies that the presence of SBNS increased the convective heat transfer coefficient significantly, and the increase was more pronounced at high concentration of SBNS. This agrees with previous study of Jones et al. (2017) which stated that if the viscosity of aggregates on the surface is too high, complete coalescence is not achieved resulting in high conductivity. The addition of SBNS to solution concentration below the CMC increases the number of charge carrier in the solution and consequently led to an increase in the conductivity. Above the CMC, additional surfactant increases the micelle concentration while the concentration of the monomer remains approximately constant (at the CMC level). Since micelle is much larger than a surfactant monomer, it diffuses more slowly through solution. This confirms the formation of $\mathrm{O} / \mathrm{W}$ emulsion at all concentrations. The emulsifying property of SBNS is because of the absence of salt in SBNS, resulting to its resistance to alkaline or acid condition (Oleszek and Hamed 2010).

Fig. 10 illustrates the drop size distribution of the SBNS emulsion. The emulsion showed a monomodal distribution pattern, and the intensity (peak) of the emulsion distribution increased with concentration until CMC. This might be due to the tendency of surfactants to aggregate. Similar results were reported by Saxena et al. (2018). They observe that as the concentration increases, there is no available space for adsorption at the interface which results in the SBNS to aggregate toward the micellar structure. At CMC (1 wt.\%), 
Fig. 7 a Emulsifying performance of SBNS at room temperature $(120 \mathrm{~h}) . \mathbf{b}$ Emulsion behaviour at different salinity concentration $(120 \mathrm{~h})$

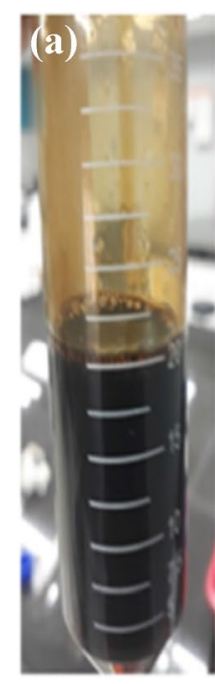

$0.1 \mathrm{wt} \%$

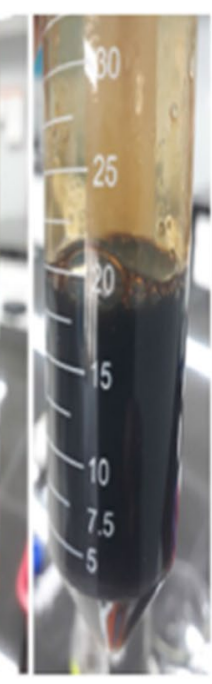

0.25 wt\%

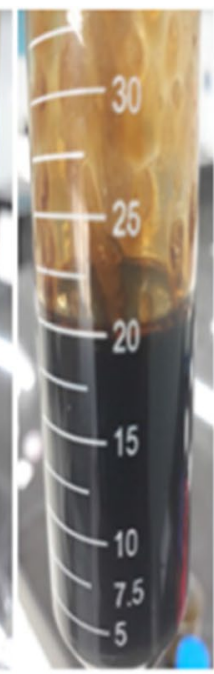

0.5 wt\%

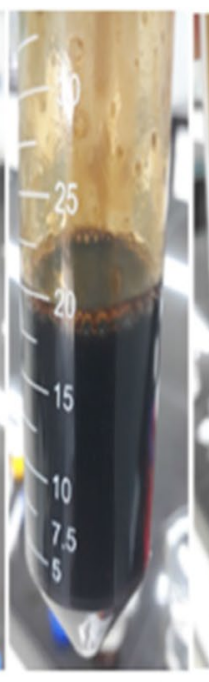

$1.0 \mathrm{wt} \%$

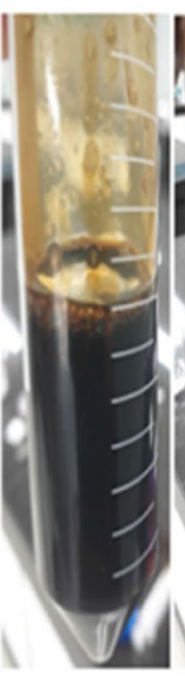

1.5 wt $\%$

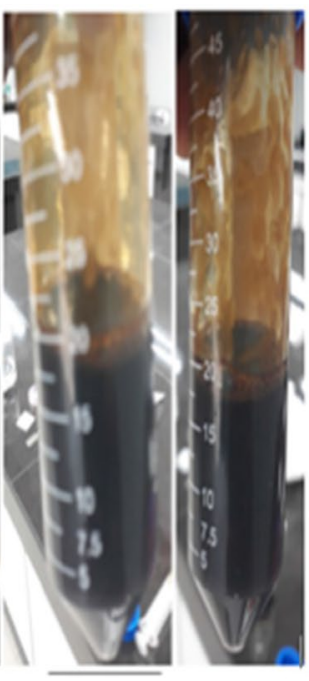

2.0 wt\% $\quad 3.0$ wt $\%$ (b)

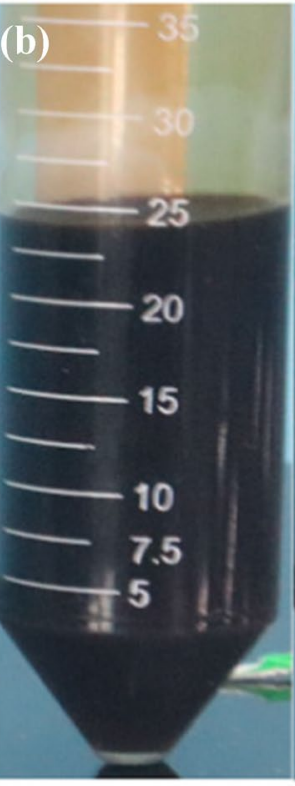

$0.9 w t \%$

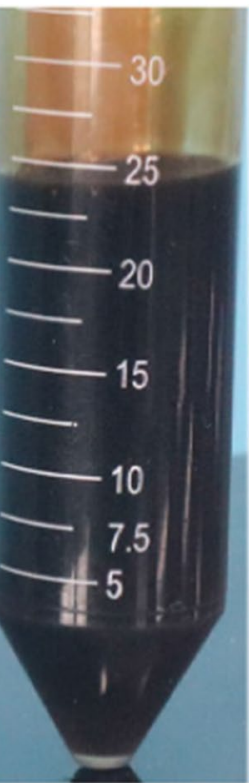

$1.5 w t \%$

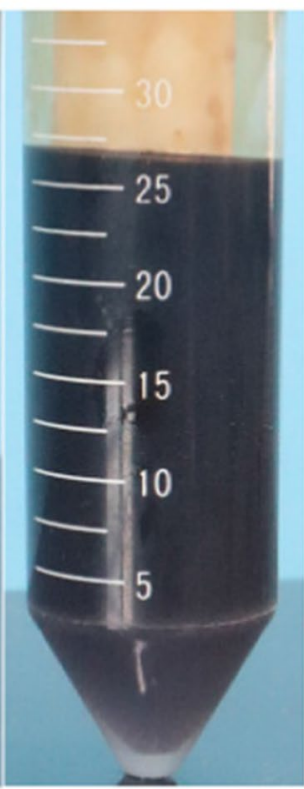

2 wt $\%$

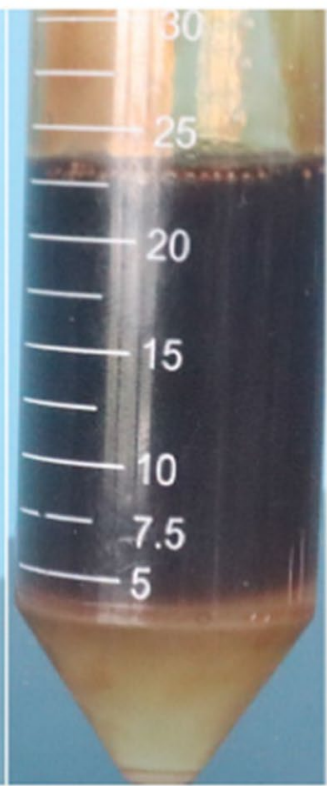

2.2 wt $\%$

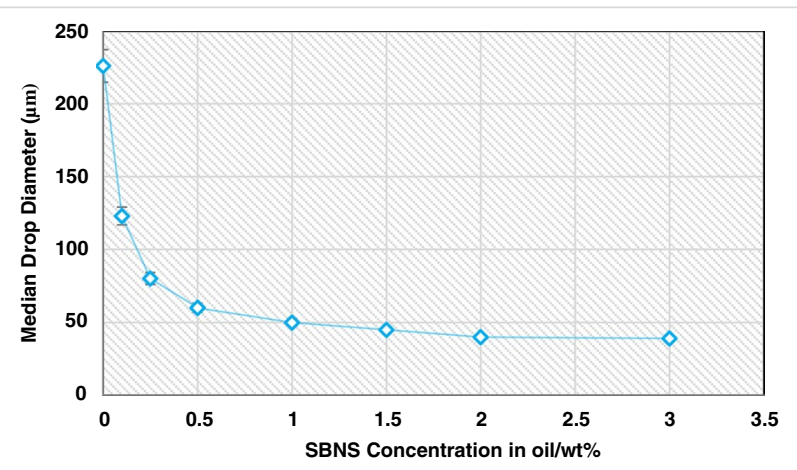

Fig. 8 Median drop diameter of emulsion the micellar structure starts forming a single peak of size range 1-121 nm. The adsorption of SBNS particles at interface stops, and the excess molecules interact with micelles at the bulk. This might have resulted to increase in micellar size (to $129 \mathrm{~nm}$ above CMC) as observed in Figure 10. This indicates that micellization is more favoured when SBNS concentration exceeds CMC (Saxena et al. 2018).

\section{SBNS flooding and recovery}

A series of core flood experiments to model water floods and surfactant floods were carried out to assess EOR prospects of SBNS. Fig. 11 shows the disparity between the total recovery of oil in secondary and tertiary modes. Thirty-six per 
Fig. 9 Conductivity of emulsion

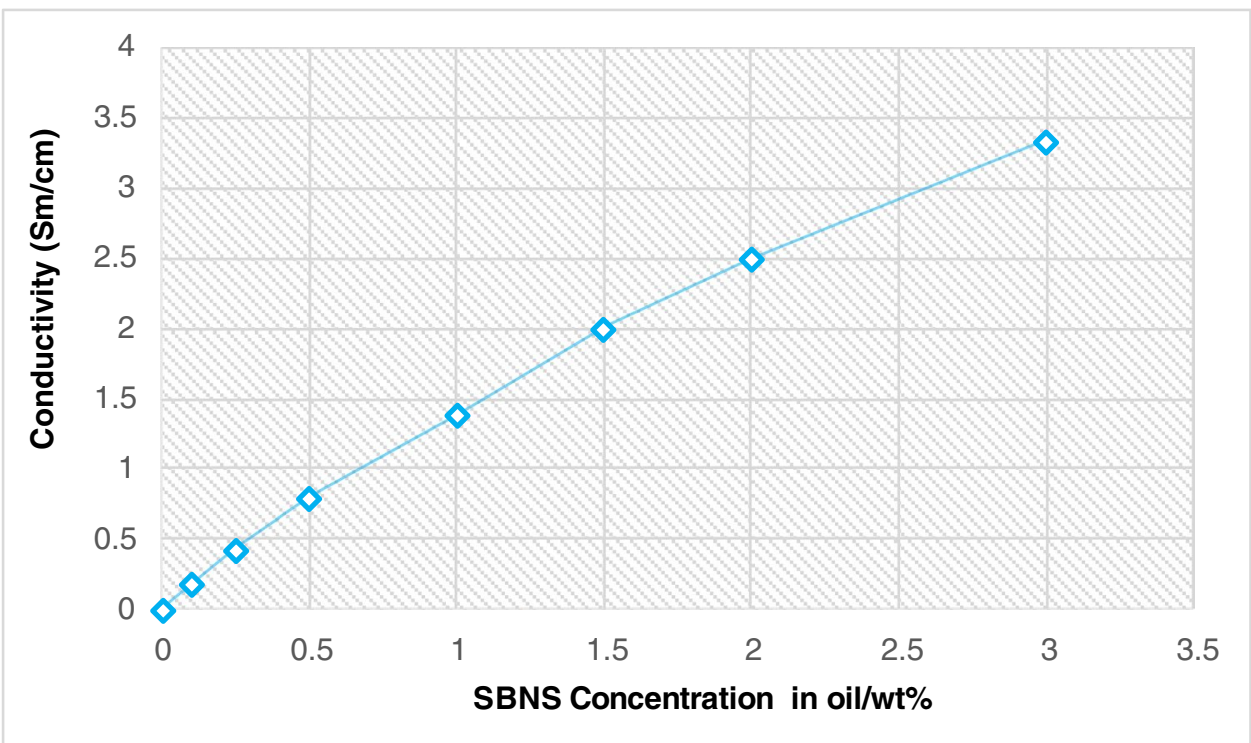

Fig. 10 Intensity-weighted emulsion distribution profile of SBNS at different concentra-

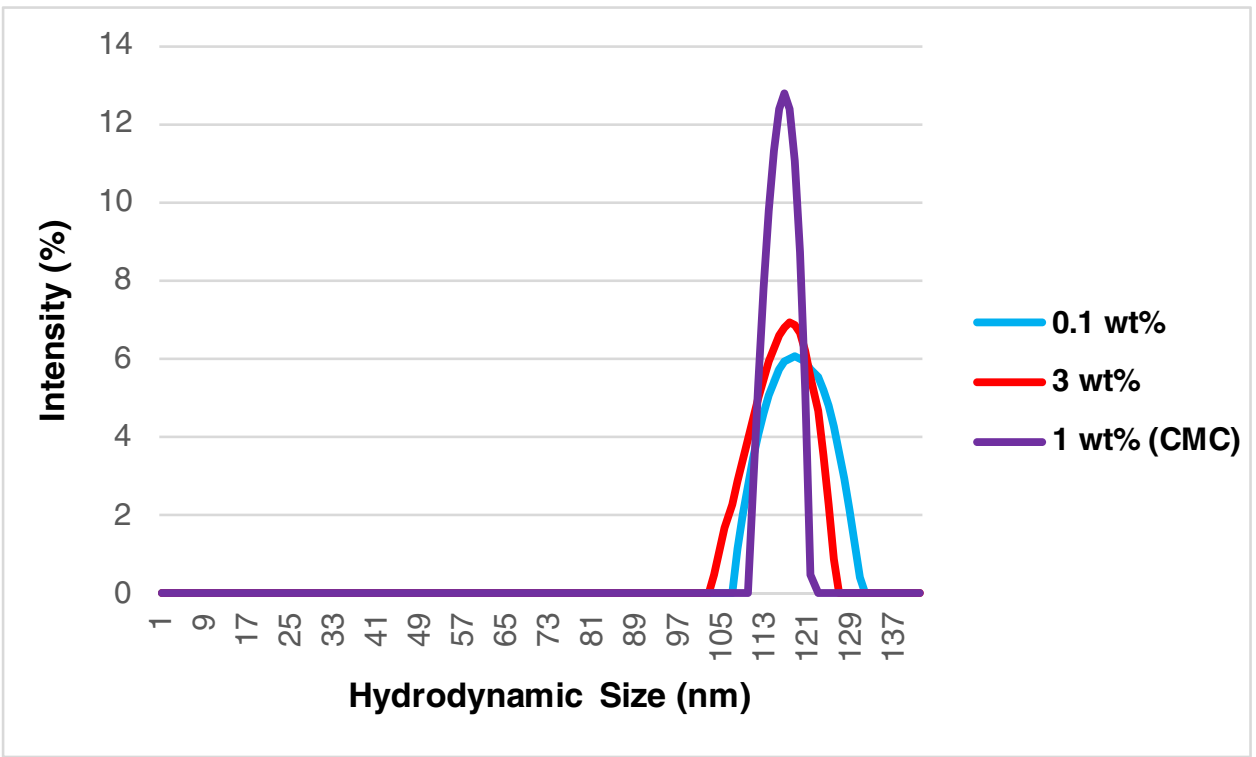

cent OOIP has been recovered through water flooding, which means ample amount of oil has been bypassed or trapped in the sandstone core. Subsequently, tertiary recovery was started; SBNS recovered 51\%, whereas TX-100 recovered $45 \%$. The recovery increased by $9 \%$ and $15 \%$ with TX-100 and SBNS, respectively. The standard deviation from the test of oil displacement was as follows: $\pm 0.25 \%$. This means that the experiment's uncertainty is minimal and reinforces the experiment's reproducibility. The additional oil recovery during the surfactant flooding process can be attributed to IFT decrement between the interface of $\mathrm{O} / \mathrm{W}$ and emulsion stability of the surfactants (Agi et al. 2020d). The higher oil recovery of SBNS compared to TX-100 is consistent with IFT and emulsion stability results. By lowering IFT of the interface of $\mathrm{O} / \mathrm{W}$ and stabilizing emulsions, capillary trapped oil in the rock pores will be mobilized toward the production well. As depicted in Table 5, the oil displacement efficiency of SBNS performs comparatively well to oil recovery reported for viscoelastic surfactants and biosurfactants in previous studies (Alsabagh et al. 2021; Hu et al. 2021).

\section{Conclusions}

This work carried out feasibility studies of an eco-friendly surfactant as a new natural EOR surface-acting agent. The surfactant was extracted from plant material and characterized using FTIR and HPLC. EOR mechanisms of SBNS were compared with non-ionic commercial surfactant 
Fig. 11 Cumulative oil recovery of surfactant flooding
Table 5 Comparison of SBNS with other surfactants in previous studies

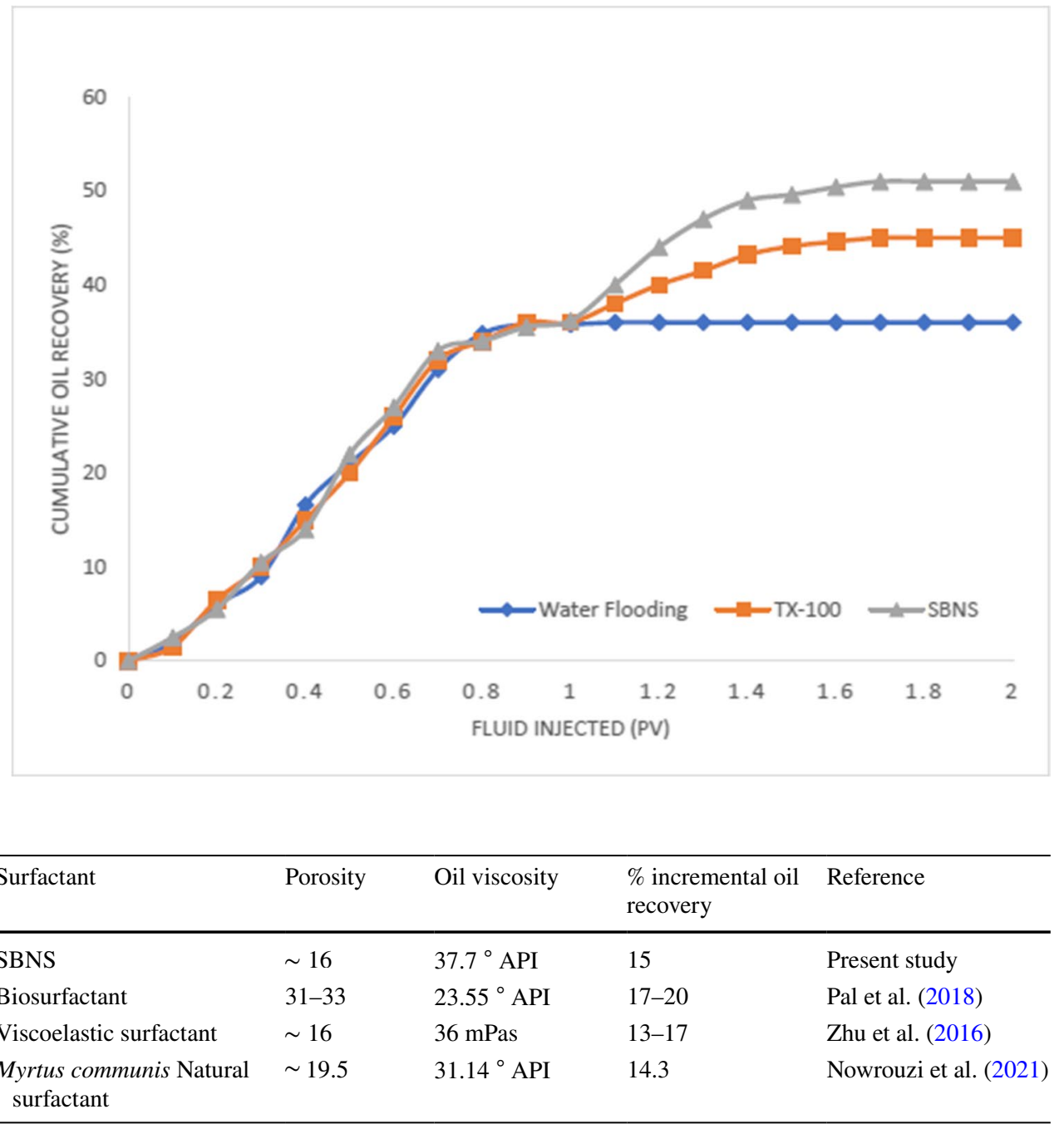

(TX-100). The following conclusions were drawn based on the experimental findings:

1. Ultrasonic preserved the bioactivity of SBNS through the mechanisms of cavitation, fragmentation, erosion, sono-capillary effect and sonoporation.

2. The FTIR results show chemical bond stretching of saponin and the HPLC result confirmed the presence of saponin. This signifies that SBNS was not degraded by the ultrasonic, and the saponin content was unaltered justifying the extraction method used.

3. The SBNS exhibited a critical micelle concentration (CMC) of $1.0 \mathrm{wt} . \%$ and reduced the IFT at the O/W interface from 18.0 to $0.97 \mathrm{mN} / \mathrm{m}$. By lowering IFT, the capillary force of trapped oil decreases, and more oil will be recovered.

4. Moreover, SBNS form stable emulsions. SBNS emulsions were stable for longer periods $(120 \mathrm{~h})$ and the median drop diameter decreases with an increase in
SBNS concentration, thus demonstrating sterling properties for EOR.

5. The oil displacement experiment shows that SBNS can effectively increase oil recovery by $15 \%$ OOIP which shows good potential application in sandstone reservoirs. Additionally, its performance compares well with conventional and biosurfactants reported in literature.

6. Future studies should evaluate the adsorption of the surfactant on sandstone and carbonate rocks. Moreover, the foaming potential of SBNS should be assessed.

\section{Declarations}

Conflict of interest The authors declare that they have no competing interests. 


\section{References}

Abbas A, Sulaiman WR, Jaafar MZ, Agi A (2018) Micelle formation of aerosol-OT surfactant in sea water salinity. Arab J Sci Eng 43(5):2515-2519

Abbas A, Moslemizadeh A, Sulaiman WR, Jaafar MZ, Agi A (2020) An insight into di-chain surfactant adsorption onto sandstone minerals under different salinity-temperature conditions: chemical EOR applications. Chem Eng Res Des 153:657-665

Abbas AH, Wan Sulaiman WR, Jaafar MZ, Gbadamosi AO, Ebrahimi SS, Elrufai A (2020) Numerical study for continuous surfactant flooding considering adsorption in heterogenous reservoir. J King Saud Univ-Eng Sci 32(1):91-99

Adil M, Lee K, Zaid HM, Latiff NR, Alnarabiji MS (2018) Experimental study on electromagnetic-assisted $\mathrm{ZnO}$ nanofluid flooding for enhanced oil recovery (EOR). PloS One 13(2):e0193518

Agi A, Junin R, Yahya A, Gbadamosi A, Abbas A (2018) Comparative study of continuous and intermittent ultrasonic ultrafiltration membrane for treatment of synthetic produced water containing emulsion. Chem Eng Process: Process Intensif 132:137-147

Agi A, Junin R, Chong AS (2018) Intermittent ultrasonic wave to improve oil recovery. J Pet Sci Eng 166:577-591

Agi A, Junin R, Alqatta AY, Gbadamosi A, Yahya A, Abbas A (2019) Ultrasonic assisted ultrafiltration process for emulsification of oil field produced water treatment. Ultrason Sonochem 59:214-222

Agi A, Junin R, Arsad A, Abbas A, Gbadamosi A, Azli NB, Oseh J (2019b) Synergy of the flow behaviour and disperse phase of cellulose nanoparticles in enhancing oil recovery at reservoir condition. PLoS ONE 14(9). https://doi.org/10.1371/journal. pone. 0220778

Agi A, Junin R, Abdullah MA, Jaafar MZ, Arsad A, Wan Sulaiman WR, Mohd Norddin MNA, Abdurrahman M, Abbas A, Gbadamosi A, Azli NB (2020) Application of polymeric nanofluid in enhancing oil recovery at reservoir condition. J Pet Sci Eng 194:107476

Agi A, Junin R, Arsad A, Abbas A, Gbadamosi A, Azli NB, Oseh J (2020) Ultrasonic-assisted weak-acid hydrolysis of crystalline starch nanoparticles for chemical enhanced oil recovery. Int J Biol Macromol 148:1251-1271

Agi A, Junin R, Abbas A, Gbadamosi A, Azli NB (2020) Effect of dynamic spreading and the disperse phase of crystalline starch nanoparticles in enhancing oil recovery at reservoir condition of a typical Sarawak oil field. Appl Nanosci 10(1):263-279

Agi A, Junin R, Gbadamosi A, Manan M, Jaafar MZ, Abdullah MO, Arsad A, Azli NB, Abdurrahman M, Yakasai F (2020) Comparing natural and synthetic polymeric nanofluids in a mid-permeability sandstone reservoir condition. J Mol Liquids 317:113947

Ali KG, Dadashi A, Daryasafar A, Moghadasi J (2015) Feasibility study of new natural leaf-derived surfactants on the IFT in an oil-aqueous system: experimental investigation. J Pet Explor Prod Technol 5:375-382

Almutairi MS, Ali M (2015) Direct detection of saponins in crude extract of soapnuts by FTIR. Nat Prod Res 29(13):1-5

Alsabagh AM, Aboulrous AA, Abdelhamid MM, Mahmoud T, Haddad AS, Rafati R (2021) Improvement of heavy oil recovery by nonionic surfactant/alcohol flooding in light of the alkane carbon number and interfacial tension properties. ACS Omega 6:1866818683. https://doi.org/10.1021/acsomega.1c01373

Alzorqi I, Sudheer S, Lu TJ, Manickam S (2017) Ultrasonic process intensification for the efficient extraction of nutritionally active ingredients of polysaccharides from bioresources. Ultrason Sonochem 35:531-540

Aydin G (2014) Production modelling in the oil and natural gas industry: an application of trend analysis. Pet Sci Technol 32(5):555-564
Aydin G (2015) Forecasting natural gas production using various regression models. Pet Sci Technol 33(15):1486-1492

Balakrishnan S, Varughese S, Deshpande A (2006) Micellar characterization of saponin from Sapindus mukorossi. Tenside Surfactants Deterg 43(5):262-268

Banerjee S, Kumar R, Mandal A, Naiya TK (2015) Use of a novel natural surfactant for improving flowability of Indian heavy crude oil. Pet Sci Technol. Taylor \& Francis 33:819-826

Bila A, Stensen JA, Torsaeter O (2020) Polymer-functionalized silica nanoparticles for improving water flood sweep efficiency in Berea sandstones. Web Conf E3S:1-12

Binks B, Philip J, Rodrigues J (2005) Inversion of silica-stabilized emulsions induced by particle concentration. Langmuir 21:3296-3302

Chemat F, Rombaut N, Sicaire A, Meullemiestre A, Fabiano-Tixier A, Albert-Vian M (2017) Ultrasound assisted extraction of food and natural products. Mechanism, Techniques, Combinations, Protocol and Applications. A Review. Ultrason Sonochem 34:540-560

Chhetri AB, Watts KC, Rahman MS, Islam MR (2009) Soapnut extract as a natural surfactant for enhanced oil recovery. Energy Sources Part A 31:1893-1903

Deymeh H, Shadizadeh SR, Motafakkerfard R (2012) Experimental investigation of Seidlitzia rosmarinus effect on oil-water interfacial tension: usable for chemical enhanced oil recovery. Sci Iran 19(6):1661-1664

Dong M, Ma S, Liu Q (2009) Enhanced heavy oil recovery through interfacial instability: a study of chemical flooding for Brintnell heavy oil. Fuel 88:1049-1056

Ferrari M, Liggieri L, Ravera F (1998) Adsorption properties of $\mathrm{C}_{10} \mathrm{E}_{8}$ at the water-hexane interface. J Phys Chem B 102(51):10521-10527

Gbadamosi AO, Kiwalabye J, Junin R, Agi A (2018) A review of gas enhanced oil recovery schemes used in the North Sea. J Pet Explor Prod Technol 8(4):1373-1387

Gbadamosi A, Junin R, Manan M, Agi A, Oseh J (2019a). Nanotechnology application in chemical enhanced oil recovery: current opinion and recent advances. In: Ariffin Samsuri (ed) Enhanced Oil Recovery Processes: New Technologies, London: Intechopen, pp 27-49

Gbadamosi A, Junin R, Manan M, Agi A, Oseh J, Usman J (2019) Synergistic application of aluminium oxide nanoparticles and oilfield polyacrylamide for enhanced oil recovery. J Pet Sci Eng 182:106345

Gbadamosi AO, Junin R, Manan MA, Yekeen N, Agi A (2020) Hybrid suspension of polymer and nanoparticles for enhance oil recovery. Polym Bull 76:6193-6230

Ghorbanizadeh S, Rostami B (2017) Surface and interfacial tension behaviour of saltwater containing dissolved amphiphilic compounds of crude oil: the role of single-salt ionic composition. Energy Fuels 31(9):9117-9124

Guo K, Li H, Yu Z (2016) In-situ heavy and extra-heavy oil recovery: a review. Fuel 185:886-902. https://doi.org/10.1016/j.fuel.2016. 08.047

Hielscher T (2005) Ultrasonic Production of Nano-Size Dispersions and Emulsions. ENS 2005, Paris, France. pp. 138-143. ffhal00166996f. ENS 138-143

Hromadkova Z, Ebringerova A, Valachovič P (1999) Comparison of classical and ultrasoundassisted extraction of polysaccharides from Salvia officinalis L. Ultrason Sonochem 5(4):163-168

Hu R, Tang S, Mpelwa M, Jiang Z, Feng S (2021) Research progress of viscoelastic surfactants for enhanced oil recovery. Energy Explor Exploit. 39:1324-1348. https://doi.org/10.1177/01445 98720980209

Hussein OS, Elraies KA, Almansour A, Husin H, Shuhili JA (2018) Beyond fracking: enhancement of shale gas desorption via 
surface tension reduction and wettability alteration. J Nat Gas Sci Eng 57:322-330

Jones FN, Nichols ME, Pappas SP (2017) Organic coating science and technology. John Wiley and Sons Inc, NJ, USA

Kumar N, Mandal A (2018) Surfactant stabilized oil-in-water nanoemulsion: stability, interfacial tension, and rheology study for enhanced oil recovery application. Energy Fuel 32(6):6452-6466

Li JW, Ding SD, X1 D (2007) Optimization of the ultrasonically assisted extraction of polysaccharides from Zizyphus jujuba cv. jinsixiaozao. J Food Eng. 80(1):176-183

Lionelli C, Mason TJ (2010) Microwave and ultrasonic processing: now a realistic option for industry. Chem Eng Process: Process Intensif 49: 885-900

Liu J, Wani OB, Alhassan SM, Pantelides ST (2018) Wettability alteration and enhanced oil recovery induced by proximal adsorption of $\mathrm{Na}^{+}, \mathrm{Cl}^{-}, \mathrm{Ca}^{2+}, \mathrm{Mg}^{2+}$, and $\mathrm{SO}_{4}{ }^{2-}$ ions on calcite. Phys Rev Appl 10:034064

Massarweh O, Abushaikha AS (2020) The use of surfactants in enhanced oil recovery: a review of recent advances. Energy Rep 6:3150-3178. https://doi.org/10.1016/j.egyr.2020.11.009

Mason T, Paniwnyk I, Lorimer J (1996) The uses of ultrasound in food technology. Ultrason Sonochem 3(3):S253-S260

Mohammad AA, Sohrad Z, Shafiei A, James L (2012) Nonionic surfactant for enhanced oil recovery from carbonates: adsorption kinetics and Equilibrium. Ind Eng Chem Res 51:9894-9905

Mohsen SB, Mojtaba PS, Mohammad Z, Milad A (2013) New surfactant extracted from Zizyphus spina-christi for enhanced oil recovery: experimental determination of staticL adsorption isotherm. J Jpn Pet Inst 56(3):142-149

Negin C, Ali S, Xie Q (2017) Most common surfactants employed in chemical enhanced oil recovery. Petroleum 3:197-211

Nowrouzi I, Mohammadi A, Manshad A (2020) Water-oil interfacial tension (IFT) reduction and wettability alteration in surfactant flooding process using extracted saponin from Anabasis Setifera plant. J Pet Sci Eng. https://doi.org/10.1016/j.petrol.2019.106901

Nowrouzi I, Mohammadi AH, Manshad AK (2021) Preliminary evaluation of a natural surfactant extracted from Myrtus communis plant for enhancing oil recovery from carbonate oil reservoirs. J Pet Explor Prod Technol 1-10. https://doi.org/10.1007/ s13202-021-01336-6

Odugbemi TO, Akinsulire OR, Aibinu IE, Fabeku PO (2007) Medicinal plants useful for malaria therapy in Okeigbo, Ondo State, Southwest Nigeria. Afr J Tradit Complement Alternat Med 4:191-198

Olajire A (2014) Review of ASP EOR (alkaline surfactant polymer enhanced oil recovery) technology in the petroleum industry: prospects and challenges. Energy 77:963-982

Oleszek W, Hamed A (2010) Saponin-Based Surfactants. In Surfactants from Renewable Resources (eds C.V. Stevens, M. Kjellin and I. Johansson). John Wiley and Sons 239-249. https://doi.org/ 10.1002/9780470686607.ch12

Pal N, Saxena N, Divya Laxmi KV, Mandal A (2018) Interfacial behaviour, wettability alteration and emulsification characteristics of a novel surfactant: Implications for enhanced oil recovery. Chem Eng Sci 187:200-212. https://doi.org/10.1016/j.ces.2018.04.062

Peshkovsky A, Bystryak S (2014) Continuous-flow production of a pharmaceutical nanoemulsion by high-amplitude ultrasound: process scale-up. Chem Eng Process: Process Intensif 82:132-136

Pordel SM, Shadizadeh SR, Jamialahmadi M (2012) A new type of surfactant for enhanced oil recovery. Pet Sci Technol 30:585-593

Ravera F, Ferrari M, Liggieri L, Miller R, Passerone A (1997) Measurement of the partition coefficient of surfactants in water/oil systems. Langmuir 13(18):4817-4820

Risal AR, Manan M, Yekeen N, Azli NB, Samin AM, Tan XK (2019) Experimental investigation of enhancement of carbon dioxide foam stability, pore plugging, and oil recovery in the presence of silica nanoparticles. Pet Sci 16:344-356

Roy R, Close K, Ghosh D (2013) Novel extraction technology for antioxidant and phytochemicals. In: Ghosh D, Das S, Bagchi D, Smarta RB, Innovation in Healthy and Functional Foods. CRC Press, Taylor and Francis Group, New York

Sahu NP, Banerjee S, Mondal NB, Mandal D (2008) Steroidal saponins. Fortschr Chem Org Naturst 89:127-141

Saxena N, Pal N, Ojha K, Dey S, Mandal A (2018) Synthesis, characterization, physical and thermodynamic properties of a novel anionic surfactant derived from Sapindus laurifolius. RSC Adv 8:24485-24499

Saxena N, Goswami A, Dhodapkar PK, Nihalani MC, Mandal A (2019) Bio-based surfactant for enhanced oil recovery: interfacial properties, emulsification and rock-fluid interactions. J Pet Sci Eng 176:299-311

Sharma OP, Kumar N, Singh B, Bhat TK (2012) An improved method for thin layer chromatographic analysis of saponins. Food Chem 132(1):671-674

Shiran BS, Skauge A (2013) Enhanced oil recovery (EOR) by combined low salinity water/polymer flooding. Energy 27:1223-1235

Sievers U, Eggers R (1996) Heat recovery in supercritical fluid extraction process with separation at subcritical pressure. Chem Eng Process: Process Intensif 35(4):239-246

Stevanato N, Silva C (2019) Radish seed oil: ultrasound-assisted extraction using ethanol as solvent and assessment of its potential for ester production. Ind Crops Prod 132:283-291

Strand S, Hognesen EJ, Austad T (2006) Wettability alteration of carbonates-effects of potential determining ions $\left(\mathrm{Ca}^{2+}\right.$ and $\left.\mathrm{SO}^{2-}\right)$ and temperature. Colloids Surf A Physicochem Eng Asp 275:1-10

Trujillo-Cayado L, Ramirez P, Alfaro M, Ruiz M, Munoz J (2014) Adsorption at the Biocompatible $\alpha$-Pinene-water interface and emulsifying properties of two eco-friendly surfactants. Colloids Surf B: Biointerfaces 122:623-629

Udochukwu U, Omeje FI, Uloma IS, Oseiwe FD (2015) Phytochemical analysis of Vernonia amygdalina and Ocimum gratissimum extracts and their antibacterial activity on some drug resistant bacteria. Am J Res Commun 3(5):225-235

Uzoho CU, Onyekonwu M, Akaranta O (2019) Chemical flooding enhanced oil recovery using local alkali- surfactant-polymer. World J Innov Res (WJIR) 1:16-24

Vinatoru M, Mason TJ, Calinescu I (2017) Ultrasonically assisted extraction (UAE) and microwave assisted extraction (MAE) of functional compounds from plant materials. TRAC-Trend Anal Chem 97:159-178

Wang Y, Li X, Lu J (2021) Experimental study of natural ions and rock interactions for seawater breakthrough percentage monitoring during offshore seawater flooding. SPE J. 1-21. https://doi. org/10.2118/201553-PA

Wang Z, Liu X, Luo H, Peng B, Sun X, Liu Y, Rui Z (2021) Foaming properties and foam structure of produced liquid in alkali/ surfactant/polymer flooding production. J Energy Resour Technol 143:1-10. https://doi.org/10.1115/1.4050498

Wieslaw O, Arafa H (2010) Saponin-based surfactants. Surfactants from Renewable Resources. In Surfactants from Renewable Resources (eds C.V. Stevens, M. Kjellin and I. Johansson). John Wiley \& Sons, Ltd. 239-248

Yekeen N, Padmanabhan E, Idris AK (2019) Synergetic effect of nanoparticles and surfactant on n-decane-water interfacial tension and bulk foam stability at high temperature. J Pet Sci Eng 179:814-830

Yekeen Yekeen N, Abdul Malik A, Idris AK, Reepei NI, Ganie K (2020) Foaming properties, wettability alteration and interfacial tension reduction by saponin extracted from soapnut (Sapindus Mukorossi) at room and reservoir conditions. J Pet Sci Eng 1-14 (in press) 
Zaeri MR, Shahverdi H, Hashemi R, Mohammadi M (2019) Impact of water saturation and cation concentrations on wettability alteration and oil recovery of carbonate rocks using low-salinity water. J Pet Explor Prod Technol 9:1185-1196

Zhong H, Yang T, Yin H, Lu J, Zhang K, Fu C (2020) Role of alkali type in chemical loss and ASP-flooding enhanced oil recovery in sandstone formations. SPE Reserv Eval Eng 23:431-445. https:// doi.org/10.2118/191545-PA
Zhu, Youyi, Fan, Jian, Liu, Xiaoxia, Jianguo Li (2016) Studies on Viscoelastic Surfactants for its Potential EOR Application in the Low Permeability Reservoirs. SPE-179551-MS, Paper presented at the SPE Improved Oil Recovery Conference, Tulsa, Oklahoma, USA. https://doi.org/10.2118/179551-MS 